\title{
Secondary Rules, the Internal Point of View and the Foundations of a Legal System: a Re-understanding to H. L. A. Hart's Theory of Legal System
}

\author{
Chen Xu \\ Post-doctoral Research Center, China University of Political Science and Law, Beijing 100088, \\ China.
}

Sephy0826@163.com

\begin{abstract}
By reflecting Austin's description of "general habitual obedience", Hart examines the difference between two characters, validity and efficacy, of legal systems and so, by this clarification, discusses the possibility that these two characters can be connected under certain social situation through what he calls "the internal point of view". According to this possibility, "Thesis of Rules" claims that the composite character of a legal system should be described as officials must generally hold the internal point of view to secondary rules, while ordinary citizens, along with officials themselves, are generally obedient to primary ones. And these can be considered as the necessary conditions and foundations of the actual existence of a legal system.
\end{abstract}

Keywords: The foundations of a legal system, validity and efficacy, secondary rules, the internal point of view.

\section{Introduction}

After excluding the Natural Law approach, legal positivists had made efforts to find necessary conditions of factual existence of a legal system. In this tradition, H. L. A. Hart had done some remarkable contributions by proposing a new thesis that solves the paradox left by John Austin. This new thesis, known as "thesis of rules", argued for the concept of law which was described as the "union of primary and secondary rules". Hart once concluded: "there are therefore two minimum conditions necessary and sufficient for the existence of a legal system. On one hand, those rules of behavior which are valid according to the system's ultimate criteria of validity must be generally obeyed, and, on the other hand, its rules of recognition specifying the criteria of legal validity and its rules of change and adjudication must be effectively accepted as common public standards of official behavior by its officials."

This paper aims to explain why Hart proposes two conditions mentioned above. These conditions can be clarified on both rational and logical level if certain distinctions are made: firstly, a distinction between "validity" and "efficacy" and the Internal Point of View which connected these two concepts are the keys for us to understand two conditions mentioned above; secondly, a legal system cannot sustain its existence without social members' general obeying primary rules, or without acceptance to secondary rules of officials.

\section{Validity and Efficacy of Law}

The first condition of factual existence of a legal system is officials must hold an internal point of view to secondary rules. According to Hart's predecessor John Austin, a legal system's validity should follow two doctrines: law are commands or orders given by political superiors to the ordinary citizens and such commands or orders must be generally obeyed by citizens in a community. Hart consider Austin's Mode of Commands as an over-simplification to validity and efficacy, for it describes, incorrectly, the complex structure of sovereignty in modern society as a simple, one-way gunmen situation.

On one hand, if someone claims that laws or a legal system has efficacy in a community, it means that officials or citizens in this community consider laws or legal system has efficacy because they actually and generally obey them. So efficacy is about subjects' factual obedience to laws or a legal 
system, although their motives vary from one to another. A thief might stop stealing out of fear of penalty, while a graduate might join the army out of his sense of honor. Efficacy, in other words, is connected with the result of an action, with the actual and general obedience to the rules without regarding what subject really has in mind.

On the other hand, validity is totally different. Hart once noted that laws or a legal system's validity was a "fact" confirmed by what he called rules of recognition. Therefore, rules of recognition provide an authoritative criteria by which officials can distinguish laws from rules that are not laws. In a mature, modern legal system, primary rules in law distinguish its validity from efficacy by introducing secondary rules. When officials or citizens want to know whether a rule is legally valid, they only need to appeal to the criteria set by the secondary rules rather than hold an external view to examine whether this rule is generally obeyed. The validity and efficacy of law is, as a result, relatively independent from each other and has no necessary conceptual connection.

Here, it is important to separate two kinds of claims: the first is that validity and efficacy of law has no necessary conceptual connection; the second is that laws or a legal system cannot be valid, from an internal point of view, without its efficacy. The first claim means that validity and efficacy can make various combinations in different social situations. For example, an ancient rule was once valid but has no efficacy now. However, an internal point of view will limit social situations in which the concept of validity is used. So a crucial key to the second claim is that an internal statement of validity and an external statement of efficacy can be, depend on various social situation, different or alike.

On the contrary, if a certain social situation is set to consider validity and efficacy of a rule system, these two concepts might have some connections in meaningful ways. Rules of chess, for instance, is not valid or has no efficacy to football player, but it must has both validity or efficacy, in the same time, to a chess player, otherwise this so-called chess player is either pretending knowing how to play the chess game or is deliberately making some wrong moves. Neither of these descriptions fit the actual situation of a chess game.

The chess game analogy can be seem as what Hart called a "simple system of rules". However, the complexity of legal system in modern society is quite different from a simple chess game, and, claimed by Hart, the legal system in modern society has a "composite character"; rules in such system divide into primary rules which grant major duties, rights and obligations and secondary rules which give primary rules validity and solve other defects of primary rules. So it might be helpful to my later argument if we take a closer look at this "composite character" of a legal system.

\section{3. "The Composite Character" of Legal System}

In this chapter, we shall examine different attitudes held by officials and citizens toward primary rules and secondary rules, and discuss what conditions are of the existence of legal system in a modern society.

We may begin with simple primary rules, which are rules that grant ordinary obligations to officials and citizens. According to Hart's theory, one necessary condition of a legal system's existence is that primary rules must have efficacy. It is, however, important to notice that there are two reasons why such rules must be actually obeyed. The first is that primary rule are, claimed by Hart, "minimum content of natural law". This means primary rule must have certain content, such as forbidding murder, robbery or giving citizens a minimum equal protection, to sustain society's most basic stability. Hart considers these contents of primary rules as a "natural necessity", and it will be impossible for a society to constantly exist if primary rules in that society do not meet the lowest standard of "natural law".

The Second reason is more obvious: primary rules are rules that constitute a legal system, so a legal system cannot be integrated or sustaining without its primary rules being generally obeyed. So members in a society should at least hold external point of view to primary rules. Citizens and officials are subjects to primary rules, and they must at least generally fulfill obligations that granted by these 
rules. It is also worth mentioning that the identities of officials which are granted by secondary rules have nothing to do with officials' obligation of obeying primary rules.

Then we should turn to secondary rules which are more complex. Firstly we should consider two different attitudes held by citizens or officials toward secondary rules. It will be easier for someone to understand this difference if he knows difference between validity and efficacy which is mentioned above. Taking rules of recognition for example, this kind of secondary rule is to set criteria that can be used to determine whether rules are law or not. Based on its functions and subjects, therefore, ordinary citizens do not have to hold an internal point of view to rules of recognition, because they are not required to take a law-identify criteria as normative ground of their behaviors. But it is also a misunderstanding that they must not or cannot hold an internal point of view to rules of recognition, because an internal attitude held by a citizen to secondary are just not necessary (though highly possible ).

But why must officials have different attitude? The most important logical reason is the function of secondary rules. Take rules of recognition for example again: the function of rules of recognition is to identify whether a rule is law, so boundary of legal system can be determined and justified. In a pre-existing legal system, rules can be determined as law not only because these rules are actually obeyed with efficacy, but also because rules have already passed validity-test set by secondary rules. So rules of recognition must have efficacy, for its lacking will lead to ridiculous situation in which no rule can be taken as law by the final authority.

This description of efficacy, however doesn't show a whole picture of the actual existence of a legal system, for rules of recognition must be accepted internally. When officials identify a rule with law by rules of recognition, they must not only just obey rules of recognition externally, but also treat rules of recognition internally as a common standard for himself and other officials. That is, in other words, if officials hold an external point of view to rules of recognition, then it is impossible for them to reach a true consensus about what law really is. "I take this rule as law because if I do not do that I will then be punished"__ this kind of thought can represent some attitudes toward secondary rules of ordinary citizens, even few officials. But if this thought is held by most of official in that society, rules of recognition, then, cannot provide criteria by which officials can use to form a true consensus about what law really is. This means a legal system will lose its logical foundation of existence. A ridiculous situation will appear if officials hold an outsider-position to rules of recognition: a legal system formed by rules are truly existing, and there are no common standard for law-making officials to decide whether a rule is law or not.

According Hart's theory, the distinction between officials and citizens shows exactly the complexity of a legal system. If we compare a pre-legal society with chess game that only has simple primary rules, then we might notice that such primary rules must be generally obeyed in a game or a society in order to provide logical foundation of its efficacy. However, in a more complex legal world, a legal system itself needs not only efficacy but also validity to check whether some rules in pre-legal world can be given that new identity. So it is officials' job to mark such rules with the label "law" and they cannot do this without holding an internal point of view to secondary rules. Otherwise there will not be a factual consensus about what law really is among officials, and this legal system will eventually fall apart. Ordinary citizens are not required to share such factual consensus, but it is true that a legal system cannot be long-existing without it. Finally, we might notice that the scope of consensus in a legal-society, which is the result of officials' internal position, has narrowed down comparing with that of pre-legal world, which is just like a simple chess game. 


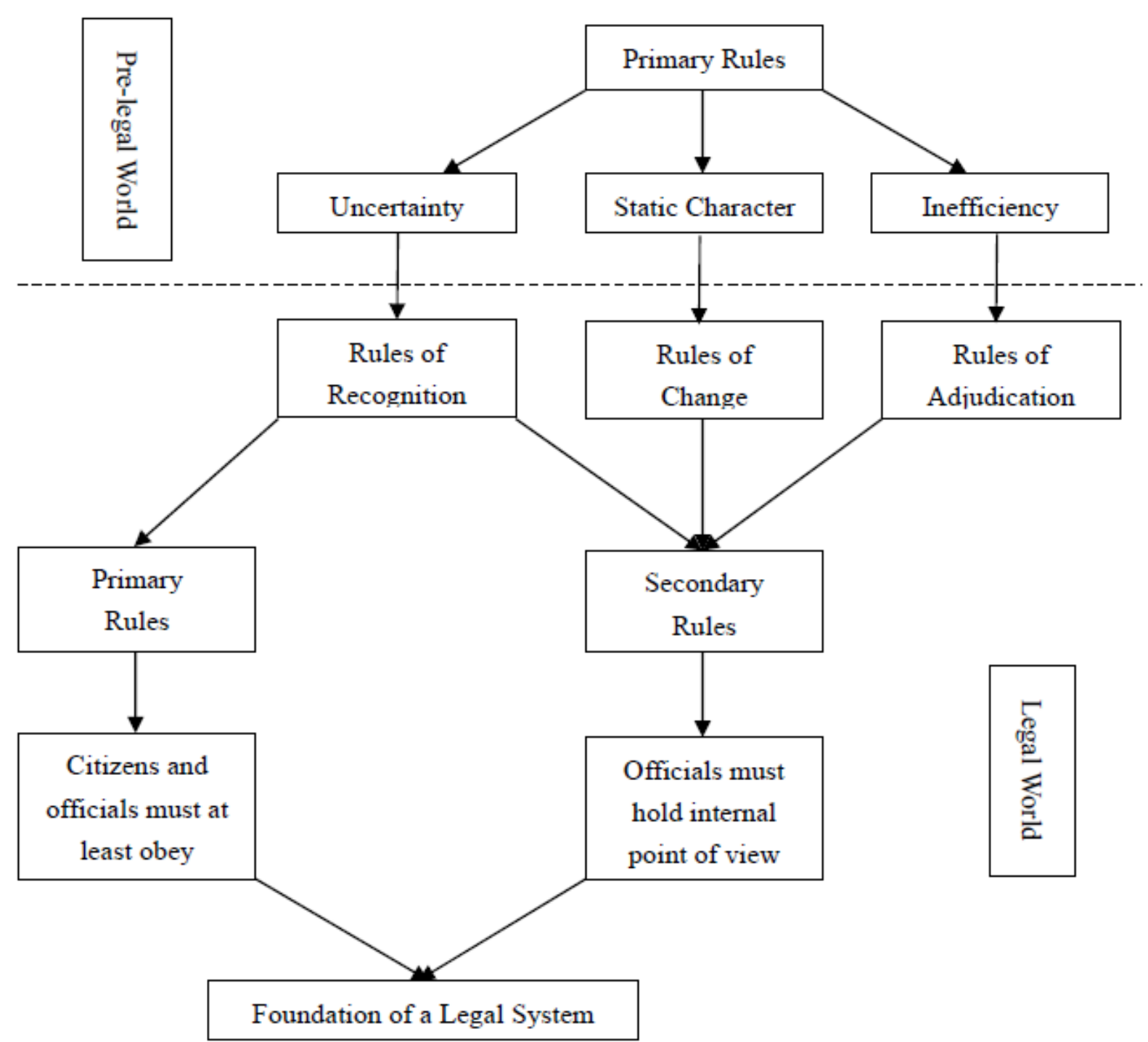

Fig 1. Pre-legal World

\section{Summary}

We may summarize this paper with a chart above. Among many theorists who have proposed criticism to Hart's theory, Ronald Dwain's is the most famous and special one. For now, it is, of course, no need to list all Working's argument, but we may consider a simple question: if rules of recognition are truly accept by officials with internal position, how can we explain hard cases in court where allegedly have "no law" at all. But we should not forget the clearness, simplicity of Hart's theory, for they are excellent qualities to a theory which dedicates to describe social facts and structure of laws.

\section{References}

[1]. H. L. A. Hart, "Positivism and the Separation of Law and Morals", Harvard Law Review, 1958, 71(4), pp.593-629.

[2]. H. L. A Hart, the Concept of Law, 2nd ed. P. Bullock and J. Razz, Clarendon Press, 1994.

[3]. Joseph Razz, the Authority of Law, Clarendon Press, 1979.

[4]. Ronald Working, Law's Empire, Harvard University Press, 1986. 